\title{
INFÂNCIAS E PÓS-COLONIALISMO
}

Antônio Miguel *

RESUMO: Discursos colonialistas sobre a infância - ao inscreverem o corpo da criança no interior de um território definido, que deve ser protegido contra a ameaça do Outro estranho e estrangeiro - constituem-no com base na mesma "gramática" dual da organização das relações humanas segundo um tipo único e fixo de vínculo político-cultural: o estado-nação. Desse modo, discursos colonialistas conformam o corpo infantil segundo a mesma lógica bélica e imperialista da exploração capitalista. Contrapondo-se a essa visão, o propósito deste artigo é caracterizar discursos pós-colonialistas que, com base na noção de hibridismo cultural, reivindicam a necessidade de se descolonizar o conceito de infância visto, ele próprio, como uma invenção colonizadora.

Palavras-chave: Infâncias. Pós-colonialismo.

\section{CHILDHOOD AND POSTCOLONIALISM}

ABSTRACT: Colonialist discourses about childhood - inscribing the child's body within a defined territory to be protected against the threat of the "Other" strange and foreign - are constituted on the basis of the same dual "grammar" of the organization of human relations, according to a unique and fixed type of cultural-political tie: the nation-state. Thus, colonialist discourses shape the child's body according to the same imperialist and war logic of capitalist exploitation. Opposing this view, the purpose of this article is to characterize postcolonial discourses that, based on the notion of cultural hybridity, claim the need to decolonize the very concept of childhood, which is considered a colonialist invention.

Keywords: Childhood. Postcolonialism.

\section{ENFANCES ET POSTCOLONIALISME}

RESSUME: Les discours colonialistes sur l'enfance - en plaçant le corps de l'enfant au sein d'un territoire défini qui doit être protégé contre la menace d'un "Autre" étrange et étranger - constituent ce corps sous la même double

\footnotetext{
* Universidade Estadual de Campinas, Faculdade de Educação, Departamento de Ensino e Práticas Culturais, Campinas, São Paulo, Brasil. E-mail de contato: miguel37.unicamp@gmail.com.
} 
"grammaire" de l'organisation des relations humaines selon un type unique et fixe de lien politico-culturelle: l'État-nation. Ainsi, les discours colonialistes façonnent le corps de l'enfant selon la même logique de guerre et impérialiste de l'exploitation capitaliste. En opposition à ce point de vue, le but de cet article est de caractériser les discours postcoloniaux qui reposent sur la notion d'hybridité culturelle, affirmant la nécessité de décoloniser le concept de l'enfance, lui même considéré comme une invention coloniale.

Mots-clés: Enfances. Postcolonialisme.

Em todo lugar sou estrangeira, menos na minha casa. Em todo lugar sou estrangeira, menos na minha casa. E mesmo na minha casa, nenhum habitante sabe Que o gosto justo da água É aquele daquela água Que em minha terra se bebe.

Letra da canção Acqua Marcia, autoria de Marina Colasanti (letra) e de Ivan Lins (música).

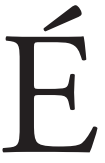

meu propósito, neste artigo, abordar o problema da infância como indissociavelmente conectado ao problema da linguagem, inscrevendo-o, sobretudo, nos rastros de significados de discursos pós-colonialistas, ainda que nem todos os interlocutores aqui chamados para essa discussão possam ser vistos como praticantes desse tipo de discurso, e mesmo que não tenham, a maior parte deles, tomado a infância como objeto destacado de estudo e pesquisa. E se discuto o problema da infância como indissociável do da linguagem, é porque os modos nem sempre conciliáveis como os próprios discursos pós-colonialistas vêm lidando com o problema da cultura seriam impensáveis fora do quadro filosófico da virada linguística que impactou irreversivelmente modos de se praticar a pesquisa, modos de se pensar os conflitos sociais e modos de se atuar no interior de movimentos sociais no mundo contemporâneo. Coloco-me, pois, no rastro de significado etimológico a que nos remete o significante da palavra infância: in-fans, sem phoné, sem som, sem voz, sem fala. Este rastro de significado revela o paradoxo a que nos remete a concepção saussureana do signo visto como o representante sonoro de um algo ausente a que supostamente se refere. Assim, o som da palavra infância nos remete a um momento da experiência humana coletiva, caracterizado pela ausência de fala, e o referido paradoxo se mostra quando tentamos rastrear o referente ausente e nos deparamos com o sem som, com a afonia, com um ausente que nos remete a outro ausente, com um significante que nos remete a outro significante, experiência esta que torna circular a nossa busca e nos sugere que a nossa experiência possível do período temporal a que denominamos infância ine- 
vitavelmente se confunde com os modos como praticamos os limites do próprio instrumento que produzimos para investigar essa experiência: a própria linguagem humana.

Foi este o modo como Agamben (2008) falou da infância para se referir ao momento em que o ser humano ainda não pode lidar discursivamente com a sua língua nativa concebida como um sistema de sinais sonoros ou gráficos. Para este autor, por ser a experiência de infância também uma experiência de apropriação de linguagem, a aquisição do poder de falar é vista como uma consequência da destruição da experiência de infância, e se há um significado social desta experiência, ele estaria associado ao desejo ético-político de constituição de uma comunidade por vir ${ }^{1}$.

Embora a infância tenha sido diversamente vista pelos participantes da pesquisa de Maher (2012) - comunidades indígenas de cada etnia, professores indígenas de cada etnia e pesquisadores acadêmicos -, ela o foi, por todos, dentro do quadro de condicionamentos normativos mútuos e complexos das relaçóes que se estabelecem entre os problemas da linguagem, da identidade cultural, da etnicidade, da cultura e da territorialidade. No contexto de tensão que se estabelece entre discursos colonialistas e pós-colonialistas e entre diferentes modos de se pensar o problema da infância dentro desse quadro, penso ser politicamente relevante perguntar:

- Deveríamos persistir na distinção saussureana que opóe línguas nacionais concebidas como sistemas e diferentes modos de se praticar essas línguas, ou investir em concepçóes de linguagens no plural, que considerassem não só a língua nativa, mas também, os diferentes sistemas simbólicos de comunicação e expressão em seus diferentes usos?

- Deveríamos persistir em concepçóes estáticas e produtivistas de cultura que a veem como conjunto de artefatos, costumes e práticas comunitárias territoriais de longa duração, ou investir em concepçóes simbólicas e dinâmicas de cultura que estabeleçam vínculos constitutivos mútuos entre práticas culturais e diferentes modos de se praticar sistemas simbólicos?

- Deveríamos persistir em concepçóes puristas de identidade cultural, associadas a concepçóes preservacionistas e etnocêntricas de etnicidade, ou ver o problema da identidade cultural dentro de perspectivas híbridas, interativas e mutantes?

- Deveríamos persistir em concepçóes unidimensionais de territorialidade, concebida exclusivamente como espaço geográfico politicamente demarcado segundo concepçóes colonialistas de estado-nação, ou falarmos em territorialidades no plural, associando-as 
a diferentes espaços de circulação e trânsito de práticas culturais e de comunidades de prática que se constituem com base em diferentes tipos de vínculos identitários?

Na pesquisa de Maher, os modos de se conceber a infância e políticas educativas relativas à infância apresentaram-se, para os diferentes grupos envolvidos na pesquisa, sob o pano de fundo de tensões que parecem refletir os próprios modos como discursos pós-coloniais constituem discursos coloniais e vice-versa. Divergências interpretativas surgem. Como as comunidades indígenas em foco tendem a lidar com elas? Como algo que poderia vir a desestabilizar a identidade de suas comunidades e a provocar o desaparecimento de suas línguas nativas? Isso tende a levar ao estabelecimento de políticas linguísticas e políticas educativas unificadoras e homogeneizadoras? Políticas linguísticas e educativas não unificadoras relativas à infância tendem a ser vistas como ameaças colonialistas e estrangeiras indicadoras de desagregação cultural?

Explicitar o quadro conflitivo manifesto na pesquisa de Maher se mostra relevante, por desafiar-nos não só a nos colocarmos a questão de como poderíamos lidar com divergências interpretativas no quadro de perspectivas metodológicas interpretativas, como também a pensar em modos descolonizadores de se praticar a pesquisa acadêmica.

Sob perspectivas tipicamente pós-colonialistas, a questão relativa ao papel político da pesquisa, bem como a nossa própria confiança no poder explicativo de nossos expedientes de pesquisa, poderiam se ver abaladas sempre que o modo como mobilizamos o conceito de estado-nação como categoria analítica não se mostrar conceitual e politicamente consonante à própria concepção de cultura que orienta nossas análises culturais. Haveria consonância conceitual quando, sob uma concepção simbólico-normativa de cultura, a própria instituição estado-nação é vista como uma prática cultural transitória de gestão político-normativa das relaçóes sociais no interior de uma comunidade. Haveria dissonância política quando, sob essa mesma concepção de cultura, adotássemos um ponto de vista colonialista da instituição estado-nação, vendo-a, como afirma Bhabha (2010, p. 201), como uma forma autônoma, ideal e soberana de racionalidade política.

Uma advertência relevante em relação aos modos como realizamos análises culturais interpretativas é a constatação de que estamos sempre situados em fronteiras culturais que separam territorialidades definidas por comunidades constituídas por diferentes tipos de vínculos culturais. E daí, em práticas descolonizadoras de pesquisa, a própria noção de estado-nação deveria ser vista como um tipo particular de vínculo cultural, ainda que marcantemente constitutivo de identidades no mundo contemporâneo. Com base na percepção de que falamos sempre com linguagens fronteiriças, penso que uma das questóes capitais que discursos pós-colonialistas colocam em pauta é a que diz respeito à constituição 
de identidades culturais comunitárias e individuais, como atesta a impactante fala da nova mestiça:

Como mestiza, eu não tenho país, minha terra natal me despejou; no entanto, todos os países são meus porque eu sou a irmá ou a amante em potencial de todas as mulheres. (Como uma lésbica, eu náo tenho raça, meu próprio povo me rejeita; mas sou de todas as raças porque a queer em mim existe em todas as raças). Sou sem cultura porque, como uma feminista, desafio as crenças culturais/religiosas coletivas de origem masculina dos indo-hispânicos e anglos; entretanto, tenho cultura porque estou participando da criação de uma outra cultura, de uma nova história para explicar o mundo e a nossa participação nele, de um novo sistema de valores com imagens e símbolos que nos conectam uns aos outros e ao planeta. Soy un amasamiento, sou um ato de juntar e unir que não apenas produz uma criatura tanto da luz como da escuridáo, mas também uma criatura que questiona as definiçóes de luz e de escuro e dá-lhes novos significados. (ANZALDÚA, 1987, p. 80-81)

Comentando esta passagem da obra de Anzaldúa, Stephenson diz que:

[...] dado que os sistemas de significação predominantes desautorizam qualquer sentido político, cultural e teórico de residência para a chicana, ela figura simultaneamente como presença e ausência tanto nas representaçóes textuais quanto nos discursos prevalecentes do estado-nação. Anzaldúa reivindica as fronteiras a partir da criação de uma comunidade imaginária utópica ou de um terceiro espaço, um lar que está aberto para a ilegal, a deslocada, a pária e a Queer. Esse terceiro espaço também demanda uma forma diferente de conhecer e sentir. (STEPHENSON apud COSTA; ÁVILA, 2005, p. 693-694)

Como se observa, discursos pós-colonialistas são discursos limítrofes que se constituem nas fronteiras, por sujeitos limítrofes de carne e osso, praticantes de línguas fronteiriças, e que são muitas vezes discriminados até mesmo por outras comunidades fronteiriças que se constituem em todos os domínios territoriais nacionais ou de outra natureza. Esta é uma das razóes pelas quais extensóes metafóricas de termos geopolíticos parecem ser acionadas por discursos pós-colonialistas: tanto os cunhados para se referir a diferentes setores das ciências da terra - a geodésia, a geologia, a geografia, a topografia, a cartografia etc. -, quanto os que se referem a conceitos de disciplinas matemáticas e cibernéticas que investigam problemas espaciais abstratos: as geometrias, a topologia, a engenharia computacional, a cibernética etc. 
Por terem sido os usos econômicos e políticos dos espaços georreferenciados os fatores motivadores da constituição histórica dos discursos de todas essas ciências, eles impulsionaram e foram também impulsionados por todos os empreendimentos colonialistas mundiais; e na medida em que tais discursos ditos cientificos foram demonstrando os seus poderes de concretização de propósitos e valores subjacentes ao projeto colonial, também foram se transformando em discursos igualmente colonizadores do poder colonial. Por terem denunciado a ideologia colonizadora subjacente a esses discursos científico-tecnológicos, os discursos pós-colonialistas foram se caracterizando como discursos fronteiriços interterritoriais, ampliando metaforicamente a noção de fronteiras geopolíticas e recusando-se a praticar discursos dicotômicos polarizadores que sempre veem o bom ou o mau, o mal ou o bem, o persistentemente velho ou o originalmente novo como geopoliticamente estrangeiros:

O Terceiro Espaço de enunciações constitui a condição prévia para a articulação da diferença cultural. [...] É significativo que as capacidades produtivas desse Terceiro Espaço tenham proveniência colonial ou pós-colonial. Isso porque a disposição de descer àquele território estrangeiro pode revelar que o reconhecimento teórico do espaço-cisão da enunciação é capaz de abrir o caminho à conceituaçáo de uma cultura internacional baseada não no exotismo do multiculturalismo ou na diversidade de culturas, mas na inscrição e articulação do hibridismo da cultura. Para esse fim, deveríamos lembrar que é o "inter", isto é, o entre-lugar, que, por constituir o fio cortante da traduçáo $e$ da negociação, carrega o fardo do significado da cultura. Ele permite que se comecem a vislumbrar as histórias nacionais antinacionalistas do "povo". E ao explorar esse Terceiro Espaço, temos a possibilidade de evitar a política da polaridade e emergir como os outros de nós mesmos. (BHABHA, 2010, p. 69, grifos do autor)

Esta passagem de Bhabha é representativa do tom híbrido dos discursos pós-coloniais para os quais a dialética colonizador-colonizado parece estar sendo, de fato, considerada em sua dialeticidade, visto que eles tendem a relevar o fato de que, mesmo sob condiçóes de opressão, subordinação e violência que inegavelmente caracterizam as interaçóes sociais de qualquer natureza que se estabelecem entre colonizadores e colonizados, nem colonizadores e nem colonizados permanecem os mesmos, na medida em que, no mercado das trocas simbólicas (BOURDIEU, 2007), se um suposto monolinguismo original e tradicional do colonizado de fato é ameaçado e não se preserva, também não se preserva um suposto monolinguismo original e tradicional do colonizador. Hibridismos não caracterizam apenas práticas discursivas propriamente ditas, mas também, todas as demais práticas simbólico-culturais envolvendo colonizadores e colonizados, 
nelas incluídas práticas relativas à educação, à saúde, à alimentação, ao lazer, à sexualidade, ao gênero etc. Seria, pois, difícil sustentar que em processos interativos interculturais se possa preservar a pureza original de quaisquer práticas, o que não significa defender ou justificar a aceitação pacífica da subordinação, da imposição e da homogeneização culturais que acompanham práticas imperialistas de certas comunidades em relação a outras. Nesse sentido, a noção de hibridismo ressignifica as noçóes de cultura e de identidade cultural, sugerindo-nos que nenhuma comunidade linguística poderia ser vista, a rigor, como monolíngue.

Mais incisivamente, quer sob a perspectiva wittgensteiniana dos jogos de linguagem (WITTGENSTEIN, 1979), quer sob a perspectiva derridiana de escritura (DERRIDA, 2009) - ambas desconstrutivas de concepçóes fono, falo, etno e logocêntricas, bem como de concepçóes representacionais da linguagem -, jogos simbólicos de qualquer natureza podem ser vistos como jogos plurilíngues idiossincráticos (e não polissêmicos) e podem ser inteligíveis, mesmo para praticantes de línguas nacionais diferentes. E daí, por mais estranho que isso possa soar, todos somos poliglotas e falamos tantas línguas quantos forem os jogos de linguagem de que participamos. E dado que jogos de linguagem - em suas idiossincrasias que os distinguem de jogos polissêmicos - são jogos de práticas culturais, todas as comunidades humanas podem ser vistas como 'hibrilíngues' e 'hibriculturais', consideração esta que está na base da necessária distinçáo entre perspectivas pós-culturalistas e multiculturalistas.

O ponto de vista performativo pós-soberano de Butler $(1997,1998)$ acerca do sujeito falante, nomeadamente inspirado na concepção derridiana (DERRIDA, 1981) de disseminação e dispersão discursivas através de links semióticos feitos por citação, reinscrição, reenvios e enxertias, traduz de modo mais íntimo e fiel relaçóes assimétricas de poder que perpassam e condicionam processos conflitivos de subjetivação e identificação cultural de sujeitos fronteiriços pós-coloniais. De fato, segundo Medina (2007, p. 189),

[...] o sujeito pós-soberano de Butler é aquele que não tem soberania ou autonomia, mas tem o poder para ressignificar [...] e a capacidade de redirecionar o discurso por diferentes repetiçóes de histórias de uso, pelo caráter citacional de seu discurso [...]. Ele não tem controle total sobre a língua que fala, mas tem uma palavra a dizer na evolução desta linguagem e pode contribuir para seu destino. Fala uma língua que nunca é completamente a sua, mas uma língua que persiste somente por meio de ocasióes repetidas daquela invocação.

Assim, discursos pós-colonialistas caracterizam-se como fronteiriços por não se situarem nem no interior de e nem no exterior de, mas no entre dois ou vários. A luta que travam contra o maniqueísmo se manifesta pelo menos desde 
o surgimento da obra Orientalismo na qual o seu autor, Edward Said (2007), defendeu a tese de que o Oriente é uma invenção do Ocidente. Não é, pois, casual que rastros do pensamento filosófico de Derrida se manifestem tanto nos discursos pós-coloniais e pós-marxistas do hindu Homi Bhabha - professor de inglês e literatura americana - e da indiana Gayatri Spivak - filósofa e professora de literatura que introduziu, traduziu e comentou a obra de Derrida nos EUA -, quanto nos discursos pós-feministas da filósofa pós-estruturalista norte-americana Judith Butler. Visto que o discurso derridiano da desconstrução pode ser caracterizado como o discurso do estar entre, do estar nem lá e nem cá, ele se constitui motivado por uma luta antimetafísica contra discursos polarizadores e maniqueístas. Cragnolini definiu o movimento da desconstruçáo como um pensamento do nem/nem, que assusta por nos jogar no não-lugar indecidível do entre:

Frente à metafísica oposicional, caracterizada pelo binarismo, o desconstrucionismo se acha situado no entre das oposiçóes: nem verdade nem falsidade, nem presença nem ausência, mas sim entre. $\mathrm{O}$ entre está designando um âmbito de oscilação do pensar. [...] O entre não é um novo lugar, mas é não-lugar, impossibilidade de assentamento, constante perigo [...]. (CRAGNOLINI, apud HADDOCK-LOBO, 2008, p. 38)

Análises pós-coloniais no âmbito da pesquisa acadêmica podem também se inspirar em discursos outros. Exemplo disso é o trabalho aqui apresentado pelo Amorim (2012), explicitamente orientado pelo conceito foucaultiano-deleuziano de diagrama (DELEUZE, 2005). Nele se pode acusar rastros de uma censura metodológica ao referencial das representações sociais para a condução de análises culturais, dado que, por meio dele, multiplicidades de infâncias em imagens acabariam sutilmente se transfigurando em imagens da infância, de uma infância abstrata monocromática; em outras palavras, imagens abstratas da infância teriam sido ilegitimamente constituídas com base em modos idiossincráticos de se mobilizar a infância através de imagens.

Ainda que o próprio Amorim não o tenha feito, é oportuno perguntar:

- Sob um olhar pós-colonialista da pesquisa acadêmica em educação da infância, discursos representacionais da infância e sobre a infância não poderiam ser vistos como formas de colonização metodológica da infância e dos territórios da infância?

- Será que o nosso desejo de territorializar a infância não seria nada mais que o desejo de constituir dicotomicamente a criança como o habitante de um país estrangeiro que se opóe e opóe resistência aos habitantes do Território Científico do Mundo Adulto?

- Estaríamos nós constituindo a criança como o Outro Estrangeiro e Estranho - o mau selvagem, ateu, inferior, naturalmente corrupto, deficiente e 
deficitário, ou então, o bom selvagem rousseauniano, puro, naturalmente dotado e bem dotado, indefeso e corruptível, mas igualmente colonizáveis, cristianizáveis, aculturáveis, civilizáveis, escolarizáveis, liberalizáveis e ocidentalizáveis, e, em ambos os casos, escravizáveis e exploráveis pelo brilho sedutor do poder da mais valia do ouro estrangeiro proveniente dos estranhos territórios do Outro?

- Não estaríamos, com ciência da ciência, construindo ilegitimamente infâncias e pedagogias desenvolvimentistas, etapistas, progressivistas, darwinistas, cumulativistas, caricaturistas e capitalistas?

- Não estaríamos desfigurando infâncias ou configurando o não figurável? Poder da ciência da infância ou ciência do poder sobre a infância?

Com o conceito de diagrama ${ }^{2}$ acionado pelo Amorim, as mutaçóes das metáforas geopolíticas inspiradoras da constituição de discursos pós-colonialistas passam por um processo de desfiguração por abstração, sem abandonar, entretanto, o referente topológico-espacial no qual todas essas metáforas se baseiam. De fato, no Foucault de Deleuze o diagrama aparece como máquina abstrata que opera de modo a restabelecer a continuidade invisível entre os modus operandi de máquinas concretas acionadas com o propósito de regular e disciplinar condutas dos sujeitos. Assim, o caráter amorfo, abstrato e formal de um diagrama se caracteriza pelo seu propósito de "impor condutas quaisquer a uma multiplicidade humana qualquer". (DELEUZE, 2005, p. 43) Se é esta a forma de um diagrama operar na sua invisibilidade, então, ele poderia ser visto como o script invariante invisível que percorre todas as máquinas concretas, sem apagar as diferenças cartográficas visíveis nos modos como estas concretamente operam. Sob essa concepção cartográfica, aquilo que o diagrama foucaultiano de Deleuze tem o poder de cartografar são, a rigor, os territórios invisíveis e mutantes das relaçóes de poder que se estabelecem em diferentes campos sociais. E ao operar invisivelmente, o diagrama revela o seu poder operatório colonizador codificado em sistemas simbólicos formalizados. E isso revela não só um poder cartográfico do diagrama de diagramar o poder, como também um poder colonizador do próprio método estruturalista de pesquisa com base no qual ele opera. Tal método estrutural que opera com o propósito de se buscar estruturas invariantes por trás de transformações que dão visibilidade às diferenças, permite que mãos inescrupulosas, carregadas de desejo de poder, suponham a existência de scripts estruturais outros justamente para apagar as diferenças, reduzindo-as a um rosto típico comum: novo poder colonial do Ocidente científico, tanto sobre o Oriente quanto si próprio, desejoso de identificar supostas purezas ou impurezas comuns a fim de criminalizar supostas impurezas comuns de pessoas comuns e salvar uma suposta pureza comum de pessoas supostamente incomuns.

Esse desejo esteve na origem da produção de retratos compósitos pelo antropólogo, meteorologista, matemático e estatístico inglês Francis Galton. Primo de Charles Darwin, ele foi também inventor da impressão digital (GALTON, 
2005) e criador da palavra eugenia. O que vemos nas duas imagens ${ }^{3}$ seguintes são estudos realizados por Galton para classificar, ordenar e indexar marcas características dos dedos das mãos, segundo a maior ou menor variação que apresentam em relação às de outros dedos tomados como padróes.

\section{Figura 1}

Method of Indexing Finger-Marks

by Francis Galton

\begin{tabular}{|c|c|c|c|c|}
\hline \multirow{2}{*}{$\begin{array}{l}\text { Elementary } \\
\text { devisions }\end{array}$} & \multirow{2}{*}{ Inder } & Symbols & f Patterns. & \multirow{2}{*}{$\begin{array}{l}\text { Index } \\
\text { number }\end{array}$} \\
\hline & & symmetric. & sloped. & \\
\hline Prim & 1 & $\therefore \frac{\Omega}{b} \frac{\Omega}{c}$ & $\begin{array}{llll}\lambda & \wedge & \wedge\end{array}$ & $\operatorname{lon} 2$ \\
\hline Whorls & 3 & $\begin{array}{l}\text { @ } \\
i\end{array}$ & $\begin{array}{llll}6 & Q & 6 & Q \\
j & k & l & m\end{array}$ & $30 \mathrm{on} 4$ \\
\hline LoOP & $\bigcap_{n} \bigcap_{0}$ & 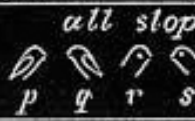 & $\rho_{t} S_{u}{ }_{r} S_{r}$ & 5 on 6 \\
\hline
\end{tabular}

\begin{tabular}{|c|c|c|c|c|c|c|c|c|c|c|c|}
\hline$L, R$ & $L, R$ & \multicolumn{4}{|c|}{$L \in f t$. } & \multicolumn{5}{|c|}{ Right. } & \multirow[b]{2}{*}{ Index } \\
\hline 123,123 & $\mathrm{~T}_{4}, \mathrm{~T}_{4}$ & 4 & 32 & 1 & $T$ & $T$ & 1 & 2 & 3 & 4 & \\
\hline $353,333_{;}$ & 35,35 & $\eta$ & (Q) & @ & e & Q & @ & @ & Q & W' & 38.2 \\
\hline 553,335 & 35,35 & 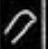 & e $P$ & @ & (อ) & (อ) & @ & e & @ & $N$ & 19.2 \\
\hline 53 & is, 55 & $\mathscr{2}$ & Q & (c) & a & Q & e & N & e & & 6.2 \\
\hline 353,653 & 35,35 & 9 & (e) 7 & e & (อ & @ & $?$ & 尺 & e & 8 & 17.1 \\
\hline 355,353 & 55,35 & ? & 28 & e & ? & e & e & 尺 & \&. & Q & 16.1 \\
\hline 355,455 & 55,35 & 7 & 17 & e & ? & e & 9 & n & N & $N$ & 49.1 \\
\hline 365,355 & 55,55 & 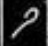 & 7 & e & $\theta$ & N & e & & & 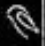 & 3.2 \\
\hline 5.555 & 35,55 & $\eta$ & $\cap \Omega$ & $q$ & e & & A & 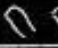 & & 8 & $21, \alpha$ \\
\hline
\end{tabular}

Fonte: Disponivel em http://www.eugenicsarchive.org/eugenics/view image.pl?id=2191

No capítulo II do seu Essays in Eugenics, Galton afirma:

A eugenia é a ciência que lida com todas as influências que melhoram as qualidades inatas de uma raça; e também com aquelas que as desenvolvem ao máximo. [...] $\mathrm{O}$ que se entende por melhoria? O que entender pela sílaba eu, da palavra engenia, que em inglês equivale a bom? Há uma considerável diferença entre 
o bem nas várias qualidades e na qualidade do caráter como um todo. O caráter depende em grande parte da proporção entre as qualidades cujo equilíbrio pode ser consideravelmente influenciado pela educação. (GALTON, 1909, p. 40)

Temos ciência dos terríveis desdobramentos de práticas eugênicas ao longo do século XX: ideologia da pureza racial, eugenia nazista e holocausto. Mas essa história não começa na Alemanha, mas sim na Inglaterra, no final do século XIX: uma encomenda feita a Galton pelo historiador e crítico literário Joseph Jacobs de produzir fotografias compósitas do tipo judeu ou do judeu típico, a partir de fotografias de meninos trabalhadores judeus. (SEKULA, 1992, p. 386) Em 1878, Galton escreveu um livro chamado Retratos Compósitos e, junto com Jacobs, escreveu ensaios publicados em números sucessivos do periódico semanal britânico The Photographic News, nos quais apareceram não só retratos compósitos do tipo judeu (Figura 2), como também retratos compósitos do criminoso típico (Figura 3), do estudante típico (Figura 4), do cientista americano tipico (Figura 5) e de uma família típica (Figura 6), como mostram as respectivas imagens seguintes:

\section{Figura 2}

Illustrations of Composite Portraiture:

The Jewish Type

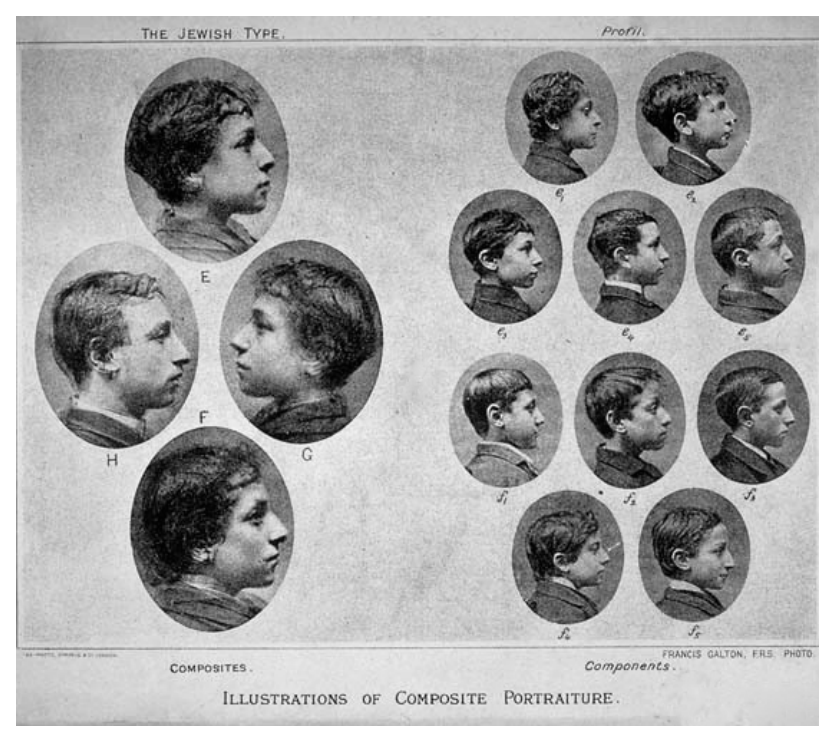



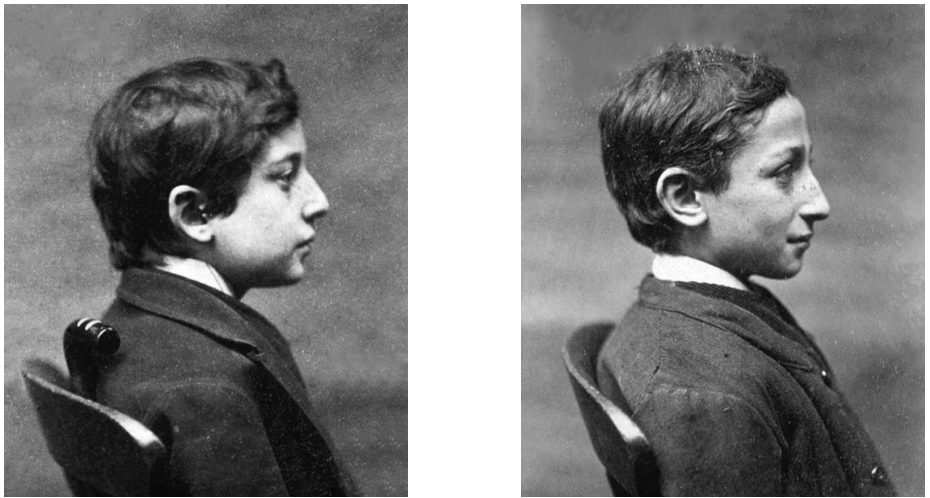

Fonte: Disponivel em http://www.eugenicsarchive.org/html/eugenics/static/images/2217.html e em http://www.eugenicsarchive.org/eugenics/image header.pl?id=2219\&printable=1\&detailed=0.

\section{Figura 3}

Composite portraits showing: features common among men convicted of crimes of violence

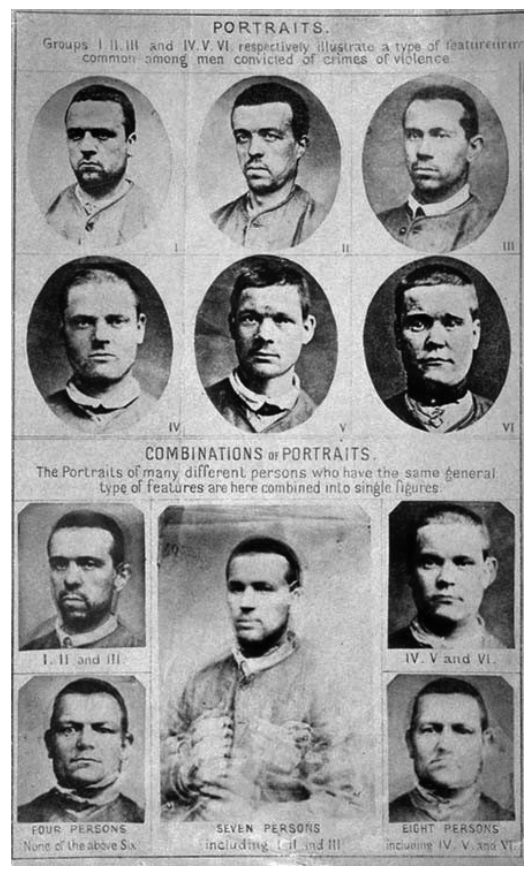

Fonte: Disponivel em http://www.eugenicsarchive.org/html/eugenics/static/images/2221.html 


\section{Figura 4}

Composite group of Irish high school students

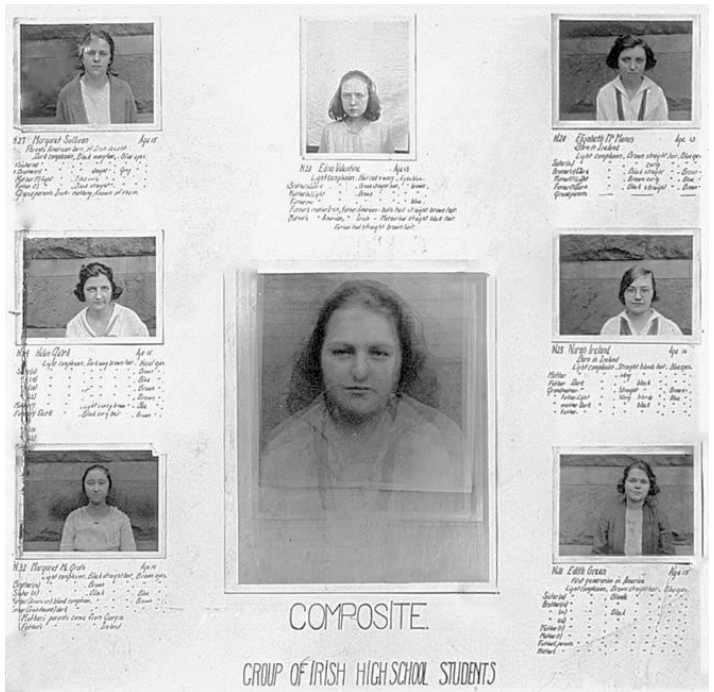

Fonte: Disponivel em http://www.eugenicsarchive.org/html/eugenics/static/images/1027.html

\section{Figura 5}

\section{Composite Portraits of Scientific Men}

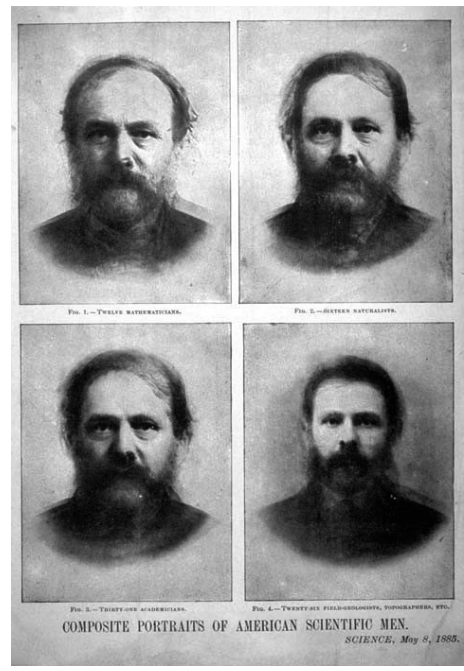

Fonte: Disponivel em http://www.dnalc.org/view/12120--Composite-Portraits-of-Scientific-Menby-Francis-Galton-Science-5-8-1885-.html 
Infâncias e pós-colonialismo

\section{Figura 6}

Composite of the portraits of six members

of the same family

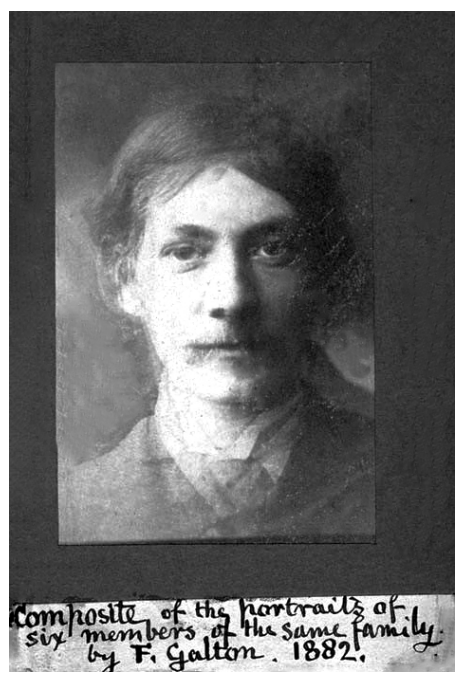

Fonte: Disponivel em http://www.eugenicsarchive.org/html/eugenics/static/images/2220.html

\section{Figura 7}

Wittgenstein and Cambridge. Family

Resemblances. A presentation

by Michael Nedo, 2011

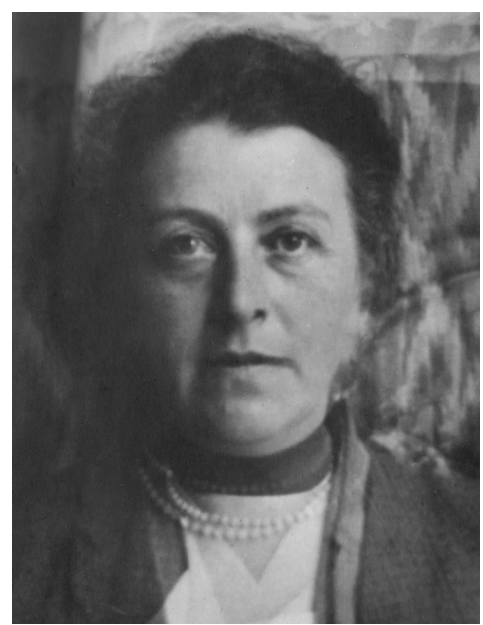

Fonte: Disponivel em http://www.editor.net/BWS/docs/ClareHallCatalogueNew.pdf 
Tal como as demais amostras típicas das imagens anteriores, também a pessoa que se vê na Figura 7, na realidade, nunca existiu.

Trata-se de uma composição fotográfica criada por meio da sobreposição de quatro fotos diferentes de faces de quatro pessoas diferentes: o filósofo austríaco Ludwig Wittgenstein e suas três irmãs de meia-idade, que podem ser vistos na foto de família (Figura 8):

\section{Figura 8}

Wittgenstein e suas irmãs

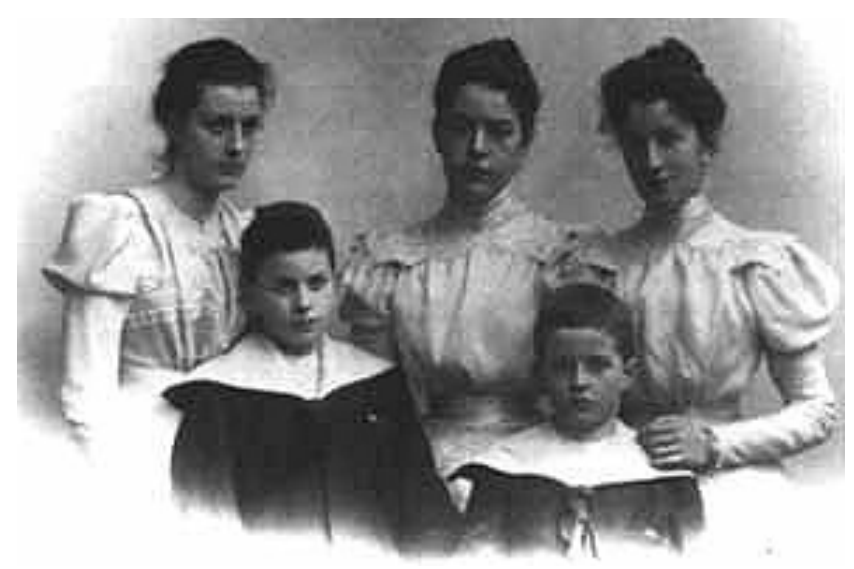

Fonte: Disponivel em http://www.wittgen-cam.ac.uk/biogre2.html

Foi o próprio Wittgenstein que, em meados da década de 1920, produziu a referida composição fotográfica com a ajuda do fotógrafo Moritz Nahr e, com base em experimentos dessa natureza, cunhou a expressão semelhanças de família. Mas é preciso fazer uma distinção ideológica de fundo entre os propósitos que orientaram a produção de retratos compósitos por Galton e por Wittgenstein. Baseado no conceito de seleção natural e no temor de degeneraçáo biológica das classes ricas e cultas inglesas de sua época, diante do aumento populacional das classes pobres, o propósito de Galton parece ter sido o de investigar processos de seleção artificial para o aprimoramento biológico e moral da espécie humana. Já o de Wittgenstein parece ter sido o de desconstruir a crença básica da ideologia eugênica e concepçóes essencialistas dos processos de significação. Não sendo o rosto compósito o representante de um suposto rosto real ou fictício, e não se podendo identificar nele alguma característica comum a todas as pessoas fotografadas, a conclusão a que chegou Wittgenstein foi que ele só poderia ser visto como a resultante imprecisa e desfocada de um rosto em que todos os tipos de 
possibilidades poderiam ser revelados, mas nunca um traço comum a todos os tipos. (NEDO, 2011)

Penso que as experimentaçóes de pensamento com imagens realizadas pelo Amorim para a constituição de suas territorialidades da infância parecem manter semelhanças de família com essa conclusão que Wittgenstein. Amorim parece ter feito um uso pós-estruturalista de diagrama que fica bem caracterizado nas palavras do Foucault deleuziano:

[...] O estribo é acionado pelo diagrama do feudalismo. [...] Foucault mostra como, [do mesmo modo], o fuzil só existe enquanto instrumento em "um maquinário cujo princípio não é mais a massa móvel ou imóvel, mas uma geometria de segmentos divisíveis e componíveis". A tecnologia é então social, antes de ser técnica. (DELEUZE, 2005, p. 49)

Assim, o diagrama pós-estruturalista opera segundo o método da decomposição e da recomposição. Mas, diferentemente do método estruturalista, o retrato compósito que se obtém após a recomposição das partes não é mais um aspecto comum, um invariante ou uma evolução contínua ou descontínua das partes que o compuseram. Amorim caracteriza sua abordagem do seguinte modo: "o que parece ser necessário pensar é na deformação, na criação de uma zona em várias formas que não são identificadas, uma vez que o comum a elas é a indiscernibilidade”. (AMORIM, 2012)

O Foucault de Deleuze está dividido em duas partes: a primeira é intitulada Do arquivo ao diagrama; a segunda, Topologia: pensar de outra forma. Penso que Amorim foi além de uma forma topológica de pensar, mesmo se a palavra topologia seja mobilizada como uma extensão metafórica de seu uso propriamente matemático. A topologia é um campo de investigação matemática que surgiu no século XIX, motivado por problemas envolvendo noções de interior, exterior, fronteira, vizinhança, cruzamento, região, estar entre etc. Se quiséssemos aqui fazer uma brincadeira, a topologia poderia ser vista como uma geometria pós-colonialista em seus conceitos e estruturalista em seus métodos. São propriedades topológicas de um objeto todas aquelas que permanecem invariantes após tal objeto ter sido submetido a certos tipos de transformaçóes que náo alterem a vizinhança de qualquer ponto a ele pertencente. Se transformarmos uma bola feita em massa de modelar em um cone ou cilindro, essas três formas são tidas como topologicamente indiscerníveis ou equivalentes. $\mathrm{O}$ mesmo não ocorre, porém, se fizermos um furo ou um rasgo na bola.

A arte modernista do século XX desfigurou o corpo humano com base em diferentes propostas topológicas ou não. Trago aqui exemplos da série de fotos intitulada A boneca: variaçóes sobre a montagem de uma menina articulada, 
produzidas na década de 1930, pelo artista plástico alemão Hans Bellmer (19021975), a partir de uma boneca em tamanho real desmontável ${ }^{4}$ também por ele 5 produzida e apresentadas a seguir:

\section{Figuras 9}

A boneca: variações sobre a montagem

de uma menina articulada
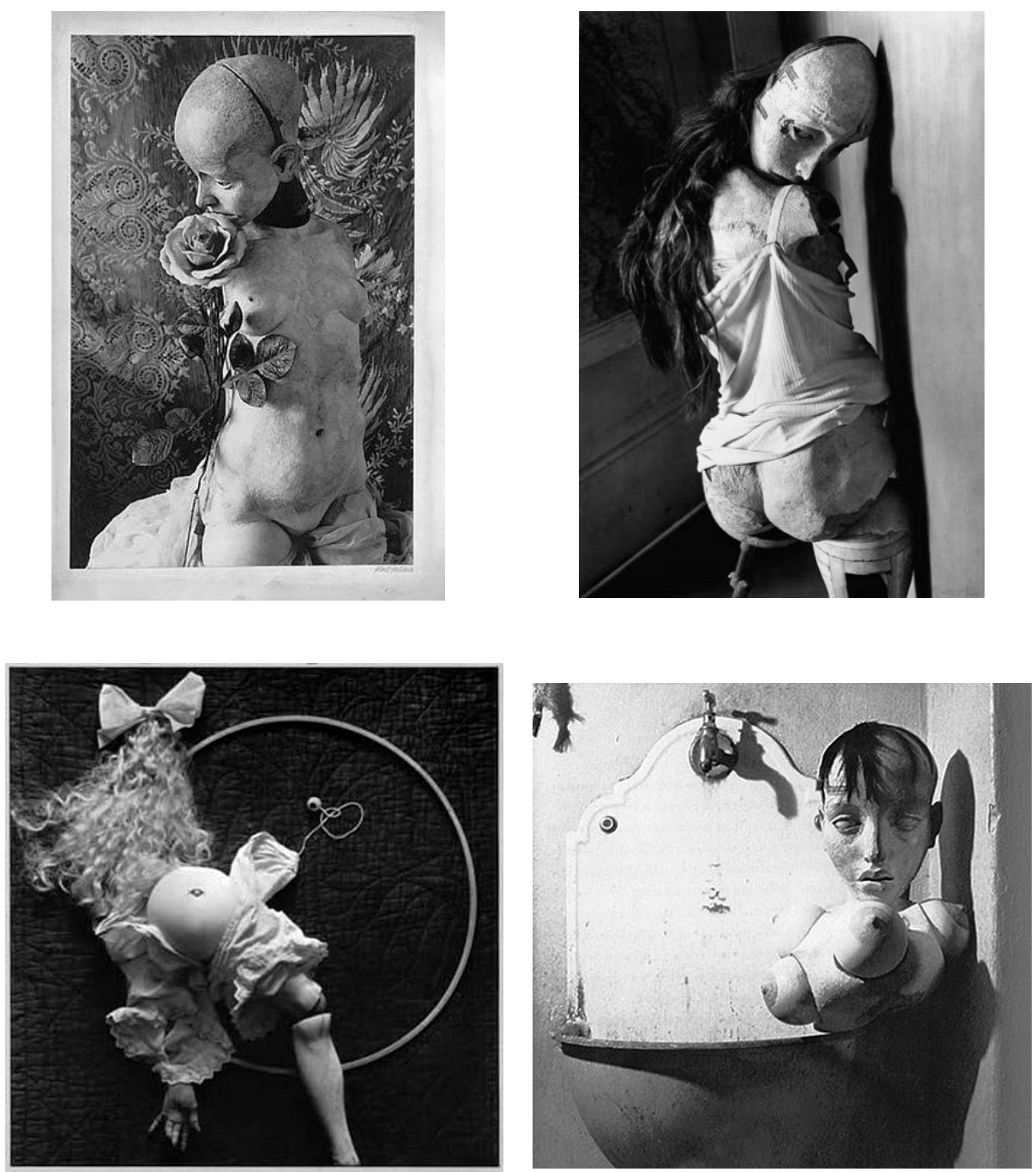


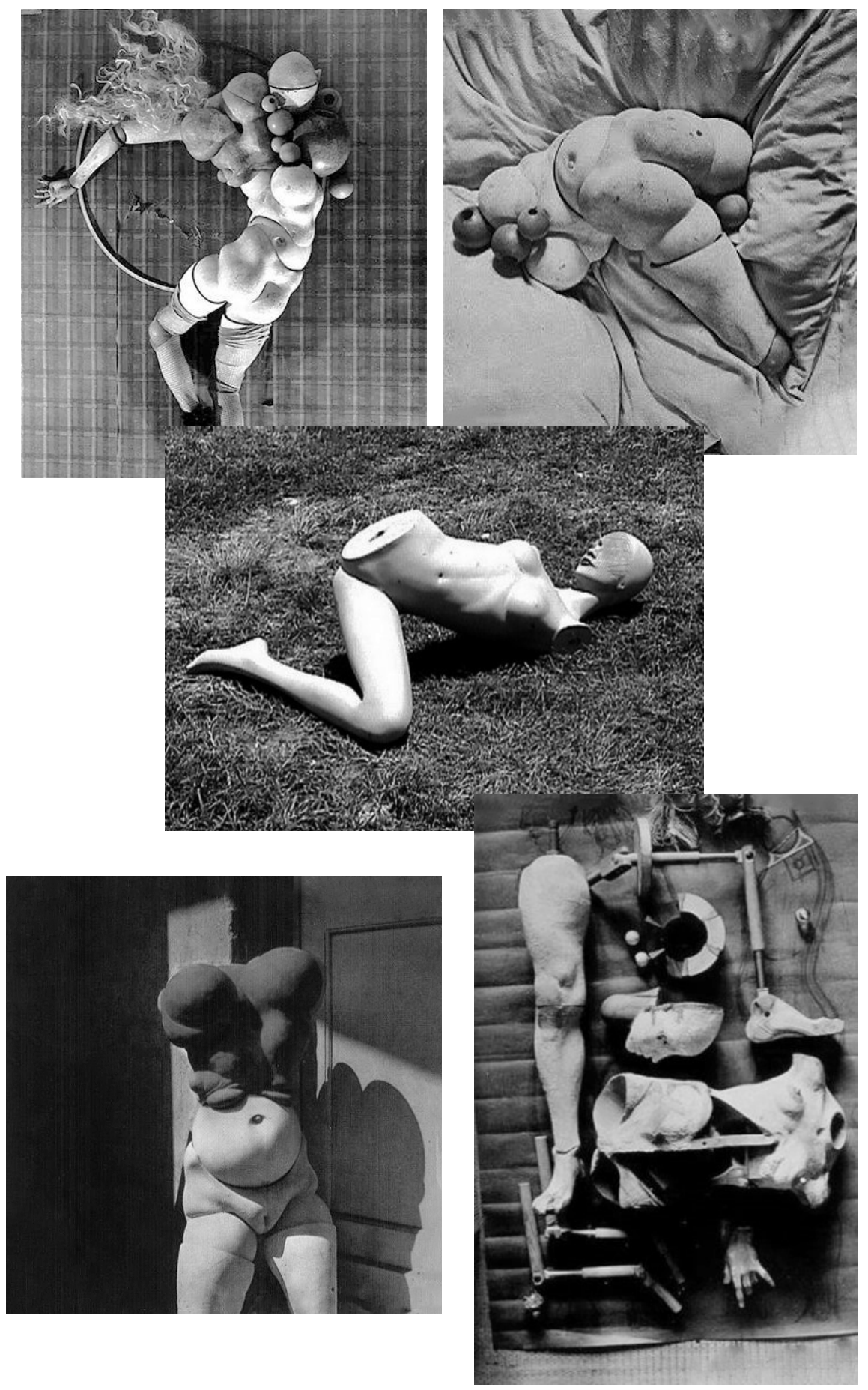


Se trago aqui estas bonecas sombrias, e não aquelas que, durante a infância de incontáveis geraçóes de crianças, construíram sonhos luminosos de vidas adultas iluminadas, é porque penso podermos ver, hoje, nelas ${ }^{6}$, imagens da denúncia pós-colonial da violência colonial sobre a mulher, a menina e a infância colonizadas ${ }^{7}$. Nem francesas nem inglesas; nem cristãs nem muçulmanas; nem humanas nem marcianas; nem esculturas nem marionetes; nem mulheres nem crianças, essas bonecas fronteiriças não estão nem aqui nem acolá, nem no exterior nem no interior, nem além nem aquém das fronteiras: habitam o entre-lugar, o não-lugar. Sem memória ou história, são compósitos atemporais; nem regradas nem desregradas, são compósitos agramaticais, como sugere Moraes (2012, p. 6667) em seu $O$ corpo impossivel:

A boneca era uma menina reconstituída depois de dilacerada: feita de fragmentos que deixavam transparecer sua estrutura interior, inteira ou decepada, careca ou com a cabeça oculta por uma boina, o sexo nu ou encoberto por uma rosa, os pés fixados no meio das costas ou as pernas surgindo do prolongamento dos braços, seu corpo de brinquedo parecia ter sido violentamente dissecado para deixar as entranhas em descoberto.

O poeta comunista francês Paul Éluard, que clandestinamente escrevia versos contra o nazismo, escreveu, inspirando-se nas bonecas de Bellmer - que haviam sido condenadas pelos nazistas ${ }^{8}$-, um conjunto de poemas em prosa intitulados Les Jeux de la poupée 9 . Entre eles, há um ${ }^{10}$ que traduzi assim:

Crianças no gabinete, há luzes encantadas, uma pistola carregada que inspira terror, uma fonte transparente, uma bacia de pedra que se espalha sobre uma cama de opalas, um caçador sem sapatos, uma menina sem cabelo, um barco no mar e o marinheiro canta, um cavalo adamascado um teatro itinerante, um grilo, penas brancas caídas de um ninho de pombas, pequenas cestas cavadas em coração creme e rosa, uma guitarra que faz faíscas e um vestido que será sempre novo. (ÉLUARD, 1968, p. 1007)

No prefácio escrito por Bellmer (apud MORAES, 2012, p. 67-68) ao Les Jeux de la poupée, ele nos fala sobre como o corpo humano pode nos aparecer quando sonhamos:

O corpo, assim como aparece no sonho, pode deslocar caprichosamente o centro de gravidade de suas imagens. Inspirado por um curioso espírito de contradição, ele superpóe a algumas delas o que suprime em outras, a imagem da perna, por exemplo, sobre a do braço, ou a do sexo sobre a axila, para realizar con- 
densaçóes, provas de analogias, ambiguidades, jogos de palavras, estranhos cálculos anatômicos de probabilidade.

No sonho de Bellmer, o corpo humano é capaz de decompor-se, recompor-se, atravessar e mudar suas fronteiras e vizinhanças. Mediante transfigurações topológicas ou não, compóe e recompóe a sua geografia de poder. Se vemos nessas multiplicidades semelhanças de família com corpos humanos é porque os Jogos da Boneca de Bellmer, bem como os poemas de Éluard que os ilustram, sáo jogos de linguagem. De fato, Bellmer (apud Moraes, 2012, p. 55), em seu Anatomia da imagem, disse que o corpo é comparável a uma frase que ele nos convida a desarticular, para que se recomponham seus conteúdos verdadeiros através de uma série ilimitada de anagramas. Mesmo que queiramos ver conteúdos verdadeiros nesta frase de Bellmer, ela não nos permite decidir se as suas bonecas seriam discursos de brinquedo ou brinquedos dos discursos; brinquedos de crianças ou crianças de brinquedo ${ }^{11}$.

Agamben (2008, p. 19) optou por orientar a escrita do seu ensaio denominado Infância e História com base na seguinte epígrafe de Leonardo: $O$ matemáticos, lançai luz sobre tal erro! O espirito não tem voz, pois onde há voz há corpo. As bonecas mudas de Bellmer não têm espírito e nem voz, mas as multiplicidades combinatórias de seus corpos de crianças de brinquedo são plurilíngues e falam, simultaneamente, todas as estranhas línguas estrangeiras de todos os pássaros migrantes e imigrantes da Terra.

\section{Notas}

1. Segundo Agamben (1993), os integrantes de tal comunidade por vir não manteriam entre si qualquer tipo de sentimento de pertença ou vínculo identitário homogeneizador, dado que constituem singularidades quaisquer sem identidades. Para ele, tal tipo de comunidade constituiria o principal inimigo do Estado, pois "[...] onde quer que estas singularidades manifestem pacificamente o seu ser comum, haverá um Tienanmen e, tarde ou cedo, surgirão os tanques armados”. (AGAMBEN, 1993, p. 68)

2. O conceito de diagrama foi acionado por Gilles Deleuze em sua análise da chamada fase genealógica da obra de Foucault, momento em que este autor desloca o foco de suas investigaçóes dos problemas relativos à constituição do saber para aqueles concernentes à genealogia do poder. (DE TONI, 2010) Em seu Foucault, Deleuze aciona pela primeira vez o conceito de diagrama referindo-se ao próprio modo como Foucault, em seu Vigiar e Punir, parece ter mobilizado essa palavra mediante a constatação da insuficiência de sua própria concepçáo óptico-arquitetural do Panóptico: "Foucault lhe deu certa vez, um nome mais preciso: diagrama, isto é, um funcionamento no qual se abstrai todo obstáculo ou atrito (...) e que deve ser destacado de todo uso especifico. O diagrama não é mais o arquivo, auditivo ou visual, é o mapa, a cartografia, coextensivos a todo o campo social. É uma máquina abstrata. Definindo-se por meio de funçóes e de materiais informais, ele ignora toda distinção de forma entre um conteúdo e uma expressão, entre uma formação discursiva e uma formação não discursiva. É uma máquina quase muda e cega, embora seja ela que faça ver e falar." (DELEUZE, 2004, p. 42) 
3. Disponível em http://www.eugenicsarchive.org/html/eugenics/static/images/2191.html.

4. Segundo Taylor (2001, p. 1), 18 fotos de um manequim feminino em tamanho real, reunidas sob o título Poupée: variations sur le montage d'une mineure articulée (Boneca: variações sobre a montagem de uma menina articulada) marcaram o primeiro aparecimento público da boneca de Bellmer, em 1934, no jornal surrealista Minotaure, e introduziram o público francês no universo de imaginação erótica desse artista: "As imagens mostravam a montagem da boneca feita em madeira, fibra de linho, gesso e cola, em construção no estúdio, ou disposta, nua, em um pano ou colchão de renda, por vezes, acompanhada de adereços sedutores: véu negro, ilhós, roupas íntimas e uma rosa artificial. Nua ou vestindo apenas camiseta de algodáo, a boneca sem braços é variadamente apresentada como um autômato esquelético, uma adolescente tímida ou como uma pilha abjeta de peças desconjuntadas. Em uma imagem incomum, o próprio artista posa ao lado de sua escultura em pé, sua presença humana tornada fantasmagórica através da exposiçấo da dupla. Aqui, o próprio corpo de Bellmer parece desmaterializar-se, ao passo que a sua garota mecânica, de peruca, com olhos de vidro, boina de lâ, mangueira flácida e um sapato único assume uma realidade preocupante."

5. Imagens disponíveis em http://artegrotesca.blogspot.com.br/2011/11/. Acesso em outubro de 2012.

6. Certamente, Bellmer não as via assim e nem as produziu para denunciar o que quer que seja. Para Taylor (2001, p. 2), a boneca teria sido por ele imaginada com base na confluência casual de três eventos de sua vida pessoal: uma visita inesperada de sua prima adolescente bonita; a sua presença em uma performance da ópera Os Contos de Hoffmann de Offenbach, em que o protagonista se apaixona, sem o saber, por uma boneca mecânica; o envio, por sua máe, de uma caixa de brinquedos que havia pertencido a ele. O impacto afetivo desses eventos, diz ele, o teriam levado a construir uma menina artificial com possibilidades anatômicas capaz de recriar os mais elevados estados de paixão, e mesmo, para inventar novos desejos. A recepção das bonecas de Bellmer foi e continua sendo polêmica. Taylor (2000, p. 3) diz que ao contrário de muitos defensores extasiados de Bellmer, não está propensa a negar a hostilidade e a agressão presente em toda a sua arte. Diz não estar disposta a denunciar fantasias de seu sexismo por desviarem-se do que é atualmente considerado politicamente correto. Diz preferir fazer, acerca de Bellmer e de suas obras, a mesma pergunta feita por Spivak: que homem é este cujo itinerário do seu desejo cria um tal tipo de texto?

7. Segundo Taylor (2001, p. 1-2), “[...] o fascínio surrealista por autômatos, especialmente o medo do estranho produzido por seu duvidoso estatuto animado/inanimado, preparou o caminho para a recepção entusiástica da boneca de Bellmer na França. Sua expressa preocupação com little girls como sujeitos de sua arte, aliás, coincidiu com a idealização surrealista da femme-enfant, uma musa cuja associação com os reinos duais da alteridade, da feminilidade e da infância inspirou artistas do sexo masculino em sua autodenominada revolta contra as forças do racional.”

8. Segundo Taylor (2000, p. 70 -71), o partido nazista prestava uma atenção microscópica para a observaçâo e regulaçâo de todos os aspectos da vida cultural no Reich. Bem antes da notória exposiçấo Arte Degenerada, inaugurada em 1937, as obras modernistas eram regularmente reunidas em $c \hat{a}$ maras de arte de horror, organizadas pelo Ministério de Goebbels para serem ridicularizadas. Nesse clima de perseguição de artistas de vanguarda, os colaboradores de Bellmer foram censurados por abuso público, sendo o próprio Bellmer visto como um degenerado e, portanto, como um artista não-germânico.

9. Em 1938, Éluard selecionou 14 fotografias da boneca ilustrando-as com curtos poemas, reunidos e publicados, em 1968, em seu Ouvres Completes. Só em 1949, o trabalho colaborativo completo entre Eluard e Bellmer, intitulado Les Jeux de la poupée (Os jogos da boneca), veio a ser publicado. (TAYLOR, 2000, p. 98, p. 251) 
10. Trata-se do segundo de um conjunto de 14 poemas intitulados Jeux vagues de la poupée. (ÉLUARD, 1968, p. 1007-1010).

11. Indiscernibilidade e vaguidade muito provavelmente intencionais, dado ter sido Bellmer, tal como Wittgenstein, leitor e admirador do filósofo, astrônomo e matemático alemão Georg-Christoph Lichtenberg (1744-1799) que, ao longo de sua vida, ocupou-se, entre outros, de problemas tais como os das relaçóes entre o corpo e a mente, a razão e o sentimento, a linguagem e o pensamento, o homem e a mulher, a ideia e a realidade (Taylor, 2000, p. 251-252). Bellmer "[...] sustentava o ponto de vista de que todos os tipos de produçáo simbólica estáo, em última instância, enraizadas na experiência corporal, tais como, por exemplo, aquelas nas quais estáo envolvidos gestos, reflexos, sons, palavras, grafismos e objetos. Para ele, figuras de linguagem tais como a hipérbole e a metáfora não pertencem unicamente à literatura, mas também, ao próprio corpo humano, o mesmo ocorrendo com os processos matemáticos que operariam não apenas no domínio abstrato, mas também na carne. Para sugerir que o corpo participa da vida intelectual e que não é a cabeça sozinha que inventa matemática, invocava o aforismo de Lichtenberg de que a nossa convicção sobre a validade de uma equação algébrica reside no cérebro, mas também, em certa medida, no polegar. (TAYLOR, 2000, p. 101-102)"

\section{Referências}

AGAMBEN, G. Infância e história. Belo Horizonte: Editora UFMG, 2008. . A comunidade que vem. Lisboa: Editorial Presença, 1993.

AMORIM, A. C. R. Palestra durante o I Seminário Internacional sobre Infâncias e Pós-Colonialismo: pesquisas em busca de Pedagogias Descolonizadas. Unicamp, Faculdade de Educação, Gepedisc, 2012.

ANZALDÚA, G. Borderlands/La frontera: the new mestiza. San Francisco: Aunt Lute, 1987.

BHABHA, H. K. O local da cultura. Belo Horizonte: Editora UFMG, 1998.

BUTLER, J. Excitable Speech. New York and London: Routledge, 1997.

. Ruled out: vocabularies of the censor. In: POST, R. (Ed.). Censorship and silencing. Indianapolis, Ind.: Getty Research Institute, 1998, p. 247-259.

. Bodies that matter. New York and London: Routledge, 1993.

BOURDIEU, P. A economia das trocas simbólicas. São Paulo: Perspectiva S. A., 2007.

COSTA, C. L.; ÁVILA, E. Gloria Anzaldúa, a consciência mestiça e o "feminismo da diferença”. Estudos Feministas, Florianópolis, v. 13, n. 3, 2005, p. 691-703.

DELEUZE, G. Foucault. São Paulo: Brasiliense, 2005.

. Foucault. Paris: Les Éditions de Minuit, 2004.

DERRIDA, J. A escritura e a diferença. São Paulo: Perspectiva, 2009.

. Dissemination. London: The Athlone Press, 1981. 
ÉLUARD, P. Oeuvres completes. Volume 1. Paris: Gallimard, 1968.

DE TONI, G. J. Leituras Deleuzianas das Relaçôes Foucaultianas de poder. 2010. Tese (Doutorado em Filosofia) - Instituto de Filosofia e Ciências Humanas, Universidade Estadual de Campinas, Campinas. 2010.

GALTON, F. Essays in Eugenics. London: The Eugenics Education Society, 1909. . Finger Prints: The Classic 1892 Treatise. New York: Dover Publications, 2005.

HADDOCK-LOBO, R. Derrida e o labirinto de inscriçôes. Porto Alegre: Zouk, 2008.

KLINGER, Diana I. Escritas de si, escritas do outro. Rio de Janeiro: 7 Letras, 2007.

MAHER, T. J. M. Palestra durante o I Seminário Internacional sobre Infâncias e Pós-Colonialismo: pesquisas em busca de Pedagogias Descolonizadas. Unicamp, Faculdade de Educação, Gepedisc, 2012.

MAHER, T. J. O bilinguismo e o aluno indígena. In: ENCONTRO SOBRE LEITURA E ESCRITA EM SOCIEDADES INDÍGENAS, 6., 2005, Campinas. Anais... Campinas: ALB, 2005. p. 97-107.

MEDINA, J. Linguagem: conceitos-chave em filosofia. Porto Alegre: Artmed, 2007.

MORAES, E. R. O corpo impossivel. São Paulo: Iluminuras, 2012.

NEDO, M. Wittgenstein and Cambridge Family Resemblances. Disponível em http://www. editor.net/BWS/docs/ClareHallCatalogueNew.pdf. Acesso em 15 jan. 2013.

PETERS, M. A.; BURBULES, N. C. Poststructuralism and educational research. Oxford: Rowman \& Littlefield Publishers, 2004.

SAID, E. W. Orientalismo. São Paulo: Cia. das Letras, 2007.

SEKULA, Allan. The body and the archive. BOLTON, R. (Ed.). The contest of meaning: critical histories of photography. London: MIT Press, 1992.

TAYLOR, S. Hans Bellmer: the anatomy of anxiety. London: The MIT Press, 2000.

TAYLOR, S. Hans Bellmer in The Art Institute of Chicago, 2001. Disponível em http:// www.artic.edu/reynolds/essays/taylor.php. Acesso em: 16 jan. 2013.

WITTGENSTEIN, L. Investigaçôes filosóficas. São Paulo: Abril Cultural, 1979.

Recebido em 30 de outubro de 2013.

Aprovado em 24 de outubro de 2014. 